\title{
Spir2; a novel QTL on chromosome 4 contributes to susceptibility to pneumococcal infection in mice
}

Laura Wisby ${ }^{1}$, Vitor E Fernandes ${ }^{2}$, Daniel R Neill ${ }^{2,3}$, Aras Kadioglu²,3, Peter W Andrew ${ }^{2}$ and Paul Denny ${ }^{1 *}$

\begin{abstract}
Background: Streptococcus pneumoniae causes over one million deaths worldwide annually, despite recent developments in vaccine and antibiotic therapy. Host susceptibility to pneumococcal infection and disease is controlled by a combination of genetic and environmental influences, but current knowledge remains limited.

Results: In order to identify novel host genetic variants as predictive risk factors or as potential targets for prophylaxis, we have looked for quantitative trait loci in a mouse model of invasive pneumococcal disease. We describe a novel locus, called Streptococcus pneumoniae infection resistance 2 (Spir2) on Chr4, which influences time to morbidity and the development of bacteraemia post-infection.

Conclusions: The two quantitative trait loci we have identified (Spir1 and Spir2) are linked significantly to both bacteraemia and survival time. This may mean that the principle cause of death, in our model of pneumonia, is bacteraemia and the downstream inflammatory effects it precipitates in the host.
\end{abstract}

Keywords: Streptococcus pneumoniae, Host susceptibility, Host genetics, Quantitative trait loci, Model organism, Mouse, Bacterial infection, Inflammation

\section{Background}

Streptococcus pneumoniae is an important pathogen, responsible for causing pneumonia, bacterial meningitis, otitis media and sepsis, in humans. Pneumococcal disease causes a considerable burden on health services and is responsible, worldwide, for over 1.2 million deaths per year in children under the age of 5 years, with many of these cases occurring in developing countries [1].

New developments in conjugate vaccines are exciting but are based on the polysaccharide capsule of the pneumococcus and with more than 90 pneumococcal serotypes and genetic exchange of the capsular loci between S. pneumoniae contributing to the enhanced evasion from serotype specific antibody [2,3] alternative vaccines are still required. The drug of choice for treatment of pneumococcal infections has, for a long time, been penicillin. However over the last 30 years, resistance to penicillin and other antibiotics in S. pneumoniae

\footnotetext{
* Correspondence: pauldenny@gene-effects.co.uk

${ }^{1}$ MRC Mammalian Genetics Unit, Harwell, Oxon OX11 ORD, UK

Full list of author information is available at the end of the article
}

has spread rapidly [4,5]. It is important to find new therapeutic targets to aid in the design and discovery of novel drugs as well as implementing genetic screening to identify individuals at risk so they can be targeted for prophylactic treatment.

Determination of genetic factors would open a radically new approach to prophylaxis and host defence. Studies of cause of death in adopted children and familial and twin studies have shown that susceptibility to infectious disease has a strong genetic component [6-9], but the genetics involved are complex and likely to be polygenic. The mapping of complex or quantitative trait loci (QTL) in naturally out-bred populations such as humans has been limited in success and identifying candidate genes has largely been restricted to association studies. Mouse models have been used to identify QTL with extensive homologies in humans and this approach has been successful in identifying infection susceptibility loci. One particularly successful example is the gene Nramp1 that was identified as a candidate for susceptibility to tuberculosis by genome wide linkage studies in

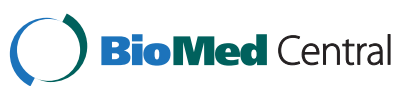


mice, and subsequently in humans by case control association studies $[10,11]$.

We have reported previously on a mouse model of susceptibility to systemic pneumococcal infection in which $\mathrm{BALB} / \mathrm{c}$ mice are resistant and CBA/Ca susceptible to intranasal infection with S. pneumoniae D39 [12]. A major QTL responsible in part for this difference in susceptibility has been mapped, in progeny of an $F_{2}$ intercross, to proximal chromosome 7 and was named Spir1 (Streptococcus pneumoniae infection resistance 1) [13]. Variants of several genes in the human population have been implicated in susceptibility to pneumococcal infection, including $\mathrm{C}$ reactive protein [14], Mannose binding lectin [15], TIRAP [16] and PTPN22 [17], but the mouse orthologs of these genes are not located in the Spir1 locus [13].

In this present study, mapping of further progeny from the $(\mathrm{BALB} / \mathrm{cOlaHsd} \times \mathrm{CBA} / \mathrm{CaOlaHsd}) \mathrm{F}_{2} \quad\left(\mathrm{CCBAF}_{2}\right)$ intercross has identified a novel QTL on chromosome 4, which we have named Spir2 (Streptococcus pneumoniae infection resistance 2). The contribution of this locus to susceptibility to pneumococcal infection was confirmed by congenic mapping.

\section{Results}

Identification of a novel QTL (Spir2) on chromosome 4 contributing to both survival time and bacteraemia Selective genotyping of $\mathrm{CCBAF}_{2}$ mice, with phenotypes representing the extremes of the response after infection challenge, identified a region of significant linkage on chromosome 4 with the traits of survival time and bacteraemia (Figure 1). The peak of linkage was located at SNP 4_80 (rs4224562) at $82.5 \mathrm{Mb}$. The QTL location on chromosome 4, estimated by the one LOD support interval, was from SNP 4_47 (rs13477699) at $50.7 \mathrm{Mb}$ to SNP 4_87 (rs3022987) at $88.2 \mathrm{Mb}$ and was $~ 38 \mathrm{Mb}$ in size. The LOD score for the peak of linkage exceeded the genome wide significance threshold of 3.10 with a LOD score of 4.56 for survival and 4.25 for bacteraemia. The QTL identified on chromosome 4 was estimated to account for $8 \%$ of the phenotypic variance. Detection of

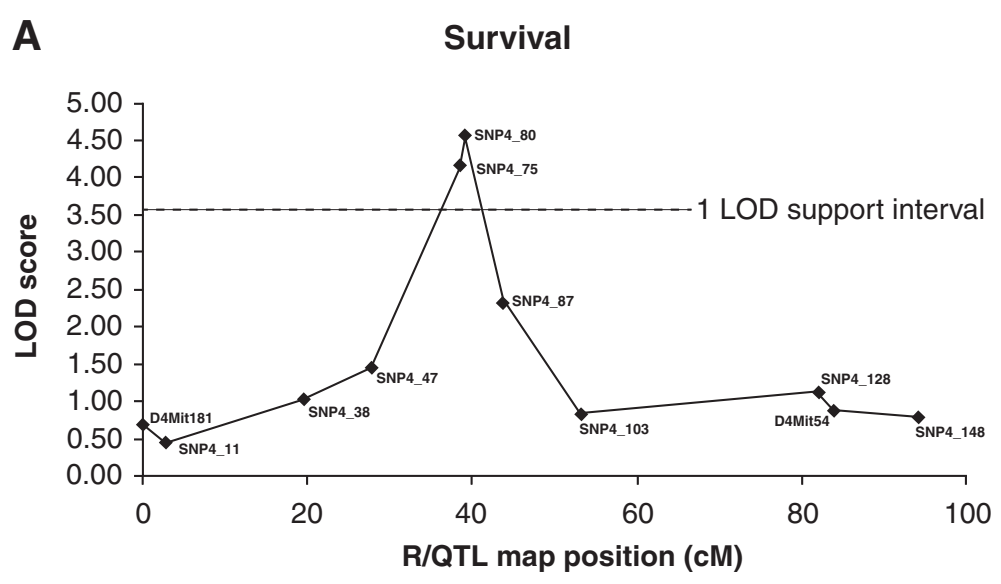

B Bacteremia

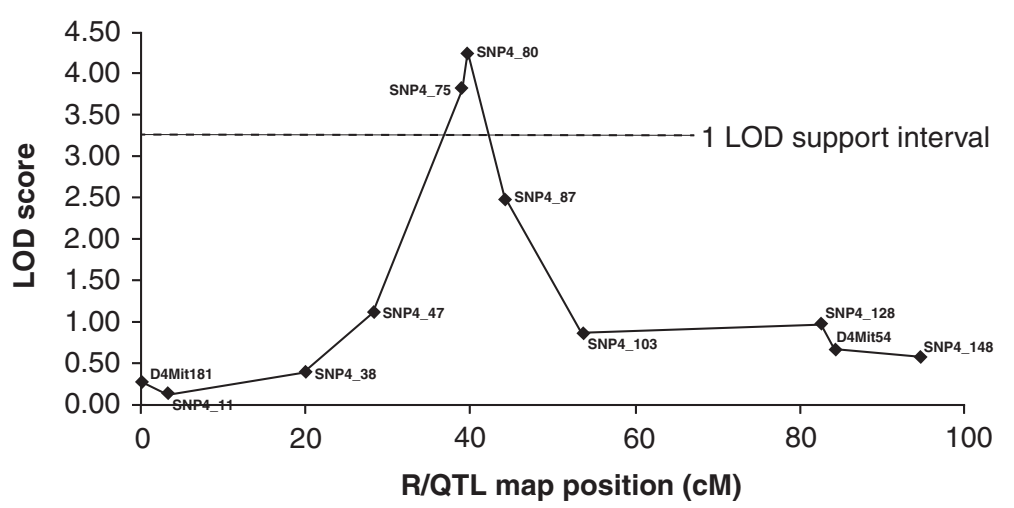

Figure 1 LOD curves for chromosome 4 for the traits of survival (A) and bacteraemia (B). The horizontal dotted line indicates the 1 LOD support interval. The peak of linkage for both traits was situated at SNP 4_80 (R/QTL analysis map position 39.2 cM, 82.5 Mb) with a LOD score of 4.56 for survival and 4.25 for bacteraemia. 
the Spir1 locus on chromosome 7 was replicated in this study, also accounting for $\sim 8 \%$ of the phenotypic variance (data not shown).

\section{Effect of genotype at Spir2 on phenotype}

In the susceptible group of $\mathrm{CCBAF}_{2}$ mice the overall distribution of genotypes at SNP 4_80 were not significantly different from the expected Mendelian ratios. However, the distribution of genotypes in the resistant group of $\mathrm{CCBAF}_{2}$ mice was significantly different from the expected 1:2:1 ratio, at SNP 4_80, if genotype had no effect $\left(x^{2}=7.2, \mathrm{df}=2, \mathrm{p}=0.027\right)$. There were a higher proportion of resistant mice heterozygous at this marker, compared to the proportion of resistant mice with CBA/ Ca or BALB/c homozygosity at SNP 4_80 (Table 1).

In order to investigate the effect of genotype at SNP 4 4 80 on the time to become moribund, a Kaplan-Meier survival analysis was performed (Figure 2A). $\mathrm{CCBAF}_{2}$ mice heterozygous for SNP 4_80 showed a significant difference in the time before exhibiting disease signs when compared to mice homozygous for BALB/c $(p=0.01)$ or $\mathrm{CBA} / \mathrm{Ca}(\mathrm{p}=0.001)$. The mean and median survival times were calculated for each $\mathrm{CCBAF}_{2}$ genotype group. The median survival time, at which $50 \%$ of the group became severely lethargic, was 44 hours for both BALB/c and $\mathrm{CBA} / \mathrm{Ca}$ genotypes. There was no median survival time calculated for the heterozygous genotype, as more than $50 \%$ of the group survived to the end of the experiment. The numbers of bacteria in the blood at 24 hours after intranasal infection were also significantly lower in $\mathrm{CCBAF}_{2}$ mice, which were heterozygous for the peak of linkage, when compared to those which were homozygous for $\mathrm{BALB} / \mathrm{c}$ or $\mathrm{CBA} / \mathrm{Ca}$ at the same SNP (Figure 2B). These data suggest that being heterozygous at this location on chromosome 4 is advantageous.

Congenic breeding confirms the contribution of the Spir2 locus to susceptibility to pneumococcal infection

The strategy of congenic breeding was used to replicate detection of the chromosome 4 QTL and to assess its contribution to the infection phenotype. Incipient congenic

Table 1 Numbers of $\mathrm{CCBAF}_{2}$ mice resistant and susceptible to pneumococcal infection, grouped by their genotype at SNP 4_80

\begin{tabular}{ccccr}
\hline \multicolumn{6}{c}{ CCBAF2 genotype at SNP4_80 } \\
\hline CBA/Ca & Heterozygous & BALB/C & $X^{2}$ & P value
\end{tabular}

\begin{tabular}{lccccc} 
Observed & & & & & \\
total & 16 & 39 & 21 & 0.71 & 0.701 \\
susceptible & $12 / 16$ & $12 / 39$ & $14 / 21$ & 5.37 & 0.068 \\
resistant & $4 / 16$ & $27 / 39$ & $7 / 21$ & 7.21 & 0.027 \\
\hline
\end{tabular}

Observed numbers of mice were compared to the expected numbers (1:2:1 ratio) if genotype had no effect using a $x^{2}$ test. strains consisting of different portions of the chromosome 4 QTL from BALB/cByJ on a CBA/CaH background, and vice versa, were produced using a marker-assisted breeding scheme.

The percentages of heterozygosity observed in the N2 and N3 males used for breeding further generations were between 37 and $42 \%$ for the N2 generation and 7 to $10 \%$ for the N3 generation. Mice with the CBA/CaH Spir2 locus on a BALB/cByJ background were bred to the N6 generation before intercrossing. These incipient congenics were named BYJCBAN6-4. Mice with the BALB/cByJ Spir2 locus on a $\mathrm{CBA} / \mathrm{CaH}$ background were bred to the N7 generation and were named CBABYJN7-4. The estimated percentage recipient genome in the final incipient congenic mice tested for infection susceptibility was 99.36 to $99.78 \%$. Therefore these mice were similar to N9 mice produced by conventional congenic breeding.

\section{BALB/CByJ Spir2 locus on CBA/CaH background (CBABYJN7-4)}

A total of 75 CBABYJN7-4 intercross mice were tested for susceptibility to S. pneumoniae infection. Of these 75 mice 18 (24\%) were resistant to pneumococcal infection and the remaining 57 (76\%) were susceptible. Six of the susceptible mice survived 50 hours or longer, while the rest only survived to between 28 and 49 hours.

A survival analysis was performed on the CBABYJN7-4 mice for each SNP on Chr4 and it was found that animals that were heterozygous at SNP 4_80 survived longer by comparison with those homozygous for the CBA/Ca allele. Similar results were found at SNP 4_103 (Additional file 1: Table S2). These results do not achieve statistical significance (SNP 4_80 p = 0.064 and SNP 4_103 p = 0.087), yet are noteworthy because they show the same trend as the Spir2 QTL detected in the $\mathrm{CCBAF}_{2}$. (Figure 3 and Additional file 2: Figure S1). There was no difference in time to morbidity between mice homozygous for BALB/ cByJ and those homozygous for $\mathrm{CBA} / \mathrm{CaH}$ at any $\mathrm{Chr} 4$ marker. There was also no significant difference in the numbers of bacteria in the blood at 24 hours postinfection in CBABYJN7-4 mice homozygous for BALB/ cByJ or CBA/CaH or heterozygous for any of the chromosome 4. SNP markers (data not shown).

A total of 64 mice could be divided into 11 haplotypes based on their combination of genotypes at SNPs 4_38 to 4_103. These groups were called CBABYJN7-4-A to $\mathrm{K}$ (Figure 4). There was no significant difference in numbers of bacteria in the blood at 24 hours postinfection between any of the CBABYJN7-4 haplotypes (data not shown). However, there was a significant difference between the survival curves of CBABYJN7-4-B and $G(p=0.014)$ with a lower risk of disease in the CBABYJN7-4-G mice compared to the CBABYJN7-4-B mice (Figure 5). 


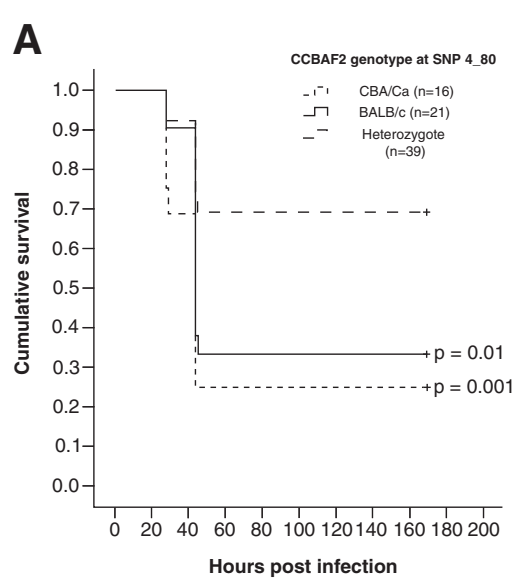

B

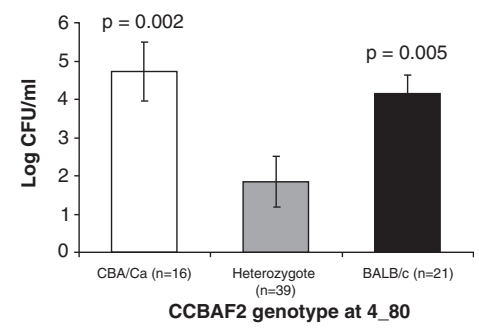

Figure 2 Infection phenotypes for CCBAF2 mice heterozygous or homozygous for CBA/Ca or homozygous for BALB/C alleles at SNP 4_80. (A) Kaplan-Meier survival curves, showing the cumulative survival (over time after intranasal infection with S. pneumoniae) for CCBAF $_{2}$ mice heterozygous, homozygous for CBA/Ca or homozygous for BALB/C at SNP 4_80. Statistical significance (compared to heterozygote, pair-wise comparison with the Log Rank test) is indicated by p values on the graph. (B) Average numbers of S. pneumoniae (Log CFU/ml) in the blood at 24 hours post-infection for $\mathrm{CCBAF}_{2}$ mice grouped by their genotype at SNP 4_80. Error bars represent the standard error of the mean. The numbers of mice in each group are shown in brackets. Statistical significance (compared to heterozygote, unpaired t-test) is indicated by $p$ values on the chart.

\section{CBA/CaH Spir2 locus on BALB/cByJ background (BYJCBAN6-4)}

A total of 26 BYJCBAN6-4 intercross mice were tested for susceptibility to infection with $S$. pneumoniae. Ten $(38 \%)$ of these mice were susceptible and 16 (62\%) were resistant to pneumococcal infection. An analysis of the survival of these mice, based on their genotype at markers on Chr4, revealed significant differences for

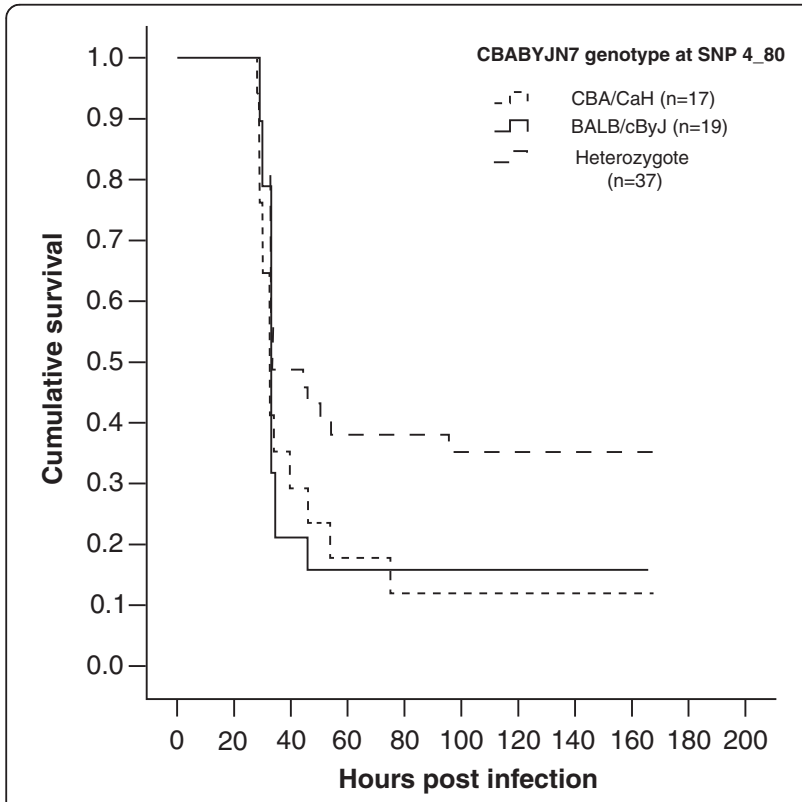

Figure 3 Kaplan-Meier survival curves, showing the cumulative survival for CBABYJN7-4 mice heterozygous, homozygous for $\mathrm{CBA} / \mathrm{CaH}$ or homozygous for BALB/CByJ at SNP 4_80.
SNPs 4_38, 4_80 and 4_103 (Figure 6A and Additional file 3: Figure S2). Mice homozygous for the BALB/cByJ allele of any of these three SNPS were at significantly less risk of disease than those homozygous for CBA/ $\mathrm{CaH}$ at the same SNP. Survival curves for mice that were heterozygous for the SNP 4_38, were significantly different from those for $\mathrm{CBA} / \mathrm{CaH}$ homozygotes $(p=0.007)$, with more heterozygotes surviving. There were no significant differences in the survival curves for animals of any of the genotypes for SNP 4_47, however this marker did follow the same trend as for SNPs 4_38, 4_80 and 4_103 (data not shown).

Numbers of bacteria in the blood of BYJCBAN6-4 mice were assessed at 24 hours post-infection. There were significantly more bacteria present in mice homozygous for the CBA/CaH allele at SNP marker 4_38 or 4_47 when compared with mice either heterozygous or homozygous for BALB/cByJ at the same SNP ( $p=0.022$ and 0.009 respectively). Although not significant, the trend was the same for SNP markers 4_80 and 4_103 (Figure 6B).

Analysis of the combination of alleles at SNPs 4_38 to 4_103 was performed on the BYJCBAN6-4 mice. Of the 26 mice, 21 could be placed into one of five different haplotypes, named BYJCBAN6-4-A to E (Figure 7). Kaplan-Meier analysis of the five haplotype groups revealed a significant difference in the survival curve of BYJCBAN6-4-A mice, which were homozygous for BALB/cByJ at all four SNPs when compared with BYJCBAN6-4-E mice, which were homozygous for CBA/ $\mathrm{CaH}$ at these SNPs $(\mathrm{p}=0.017)$ (Figure 8A). Analysis of the bacteraemia results at 24 hours post-infection also 


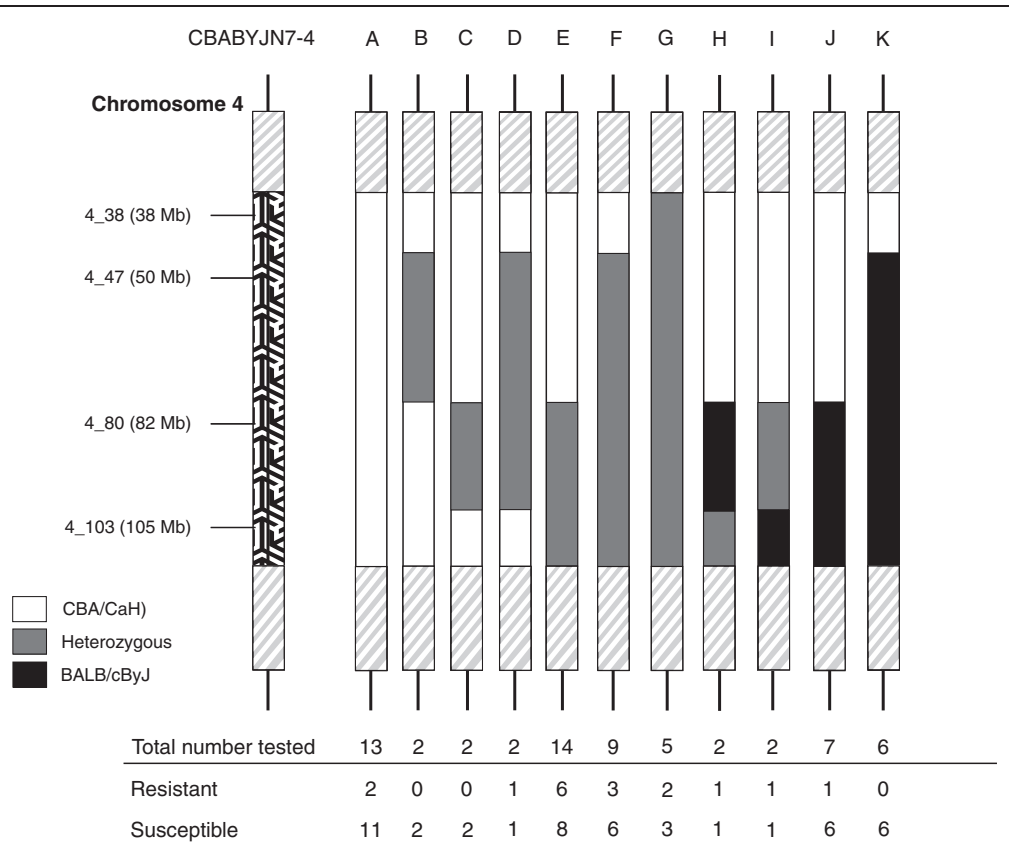

Figure 4 Diagram representing chromosome 4 from the different CBABYJN7-4 haplotype groups named CBABYJN7-4-A to K. The area spanning SNP markers 4_38 to 4_103 is highlighted with the positions of each the SNP markers used for genotyping shown on the left. Areas outside of these SNP markers (grey diagonal lines) are either homozygous for the recipient strain or heterozygous. Black represents regions homozygous for BALB/CByJ, white for regions homozygous for $\mathrm{CBA} / \mathrm{CaH}$ and those in grey are heterozygous. The total number of mice from each group that were tested can be seen with the numbers of resistant and susceptible mice below.

revealed a significant difference between BYJCBAN64-A and E mice $(\mathrm{p}=0.005)$. BYJCBAN6-4-E mice had significantly higher numbers of bacteria present in the blood when compared with BYJCBAN6-4-A mice, which had no bacteraemia at 24 hours (Figure $8 \mathrm{~B}$ ).

\section{Discussion}

Selective genotyping of $\mathrm{CCBAF}_{2}$ mice from the phenotypic extremes was successful in identifying a novel QTL on chromosome 4 (named Spir2) contributing to susceptibility to pneumococcal disease. This type of selective

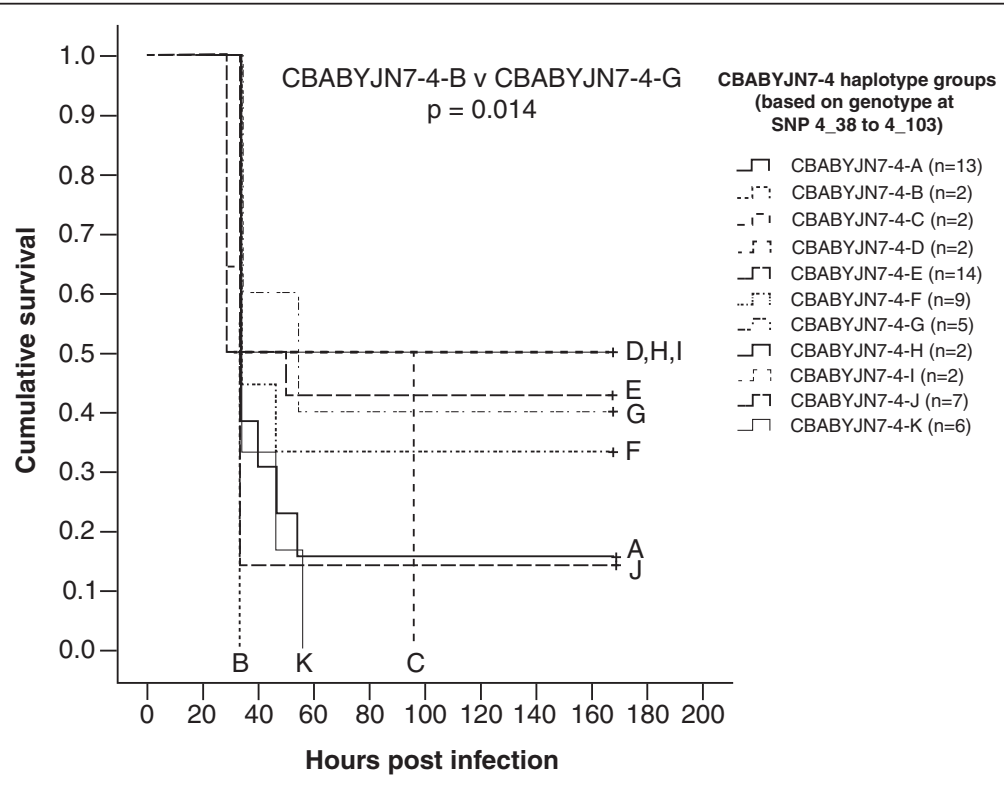

Figure 5 Kaplan-Meier survival curves showing the cumulative survival for the CBABYJN7-4 haplotype groups. The survival curve for each haplotype is labelled (A to K). Statistical significance (pair-wise comparison with the Log Rank test) is indicated by $\mathrm{p}$ values on the graph. 

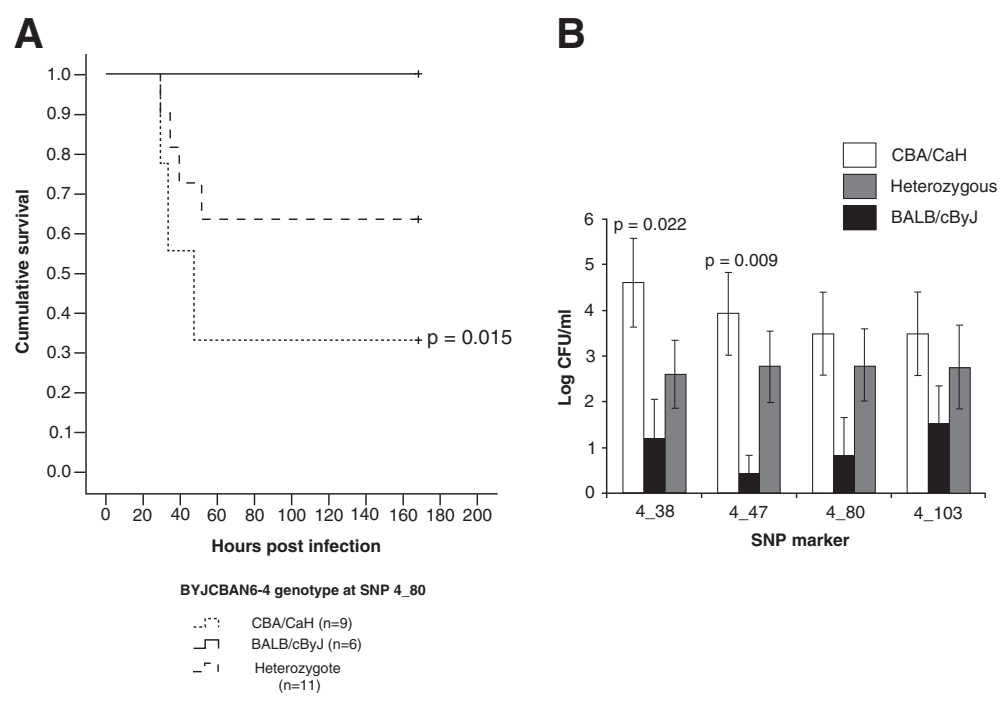

Figure 6 Infection phenotypes for BYJCBAN6-4 mice. Kaplan-Meier survival curves, showing the cumulative survival for BYJCBAN6-4 mice heterozygous, homozygous for CBA/CaH or homozygous for BALB/CByJ at SNP 4_80 (A). Statistical significance (compared to BYJCBAN6-4 mice homozygous for BALB/CByJ, pair-wise comparison with the Log Rank test) is indicated by $p$ values on the graph. (B) Average numbers of $S$. pneumoniae (Log CFU/ml) in the blood at 24 hours post-infection for BYJCBAN6-4 mice grouped by their genotype at SNPs 4_38, 4_47, 4_80 or 4_103. Error bars represent the standard error of the mean. The numbers of mice in each group are shown in brackets. Statistical significance (compared to BALB/cByJ homozygosity, unpaired $t$-test) is indicated by $p$ values on the graph.

genotyping has been implemented in various studies because it reduces laboratory costs and it is successful in gaining as much, if not more, information as genotyping the same number of random mice [18-21]. The Spir2 peak of linkage was situated at SNP 4_80 and CCBAF2 mice that were heterozygous for this SNP had both significantly longer survival times and lower levels of bacteraemia, following intranasal infection, when compared with homozygous animals. Infection challenges of the Chr4 incipient congenic strains confirmed detection of the Spir2 QTL observed in the CCBAF2 mice, but did not reduce the size of the critical region.

BYJCBAN6-4 mice, which had the Spir2 region introgressed from $\mathrm{CBA} / \mathrm{CaH}$ onto the $\mathrm{BALB} / \mathrm{cByJ}$ background, had significantly shorter survival times after infection and significantly higher levels of bacteraemia at 24 hours when compared with mice heterozygous for the QTL or homozygous for BALB/ cByJ. The effect of the QTL was different when on the $\mathrm{CBA} / \mathrm{CaH}$ background. Interestingly, although not quite significant, mice heterozygous for SNPs 4_80 and 4_103 on the $\mathrm{CBA} / \mathrm{CaH}$ background were less susceptible than those homozygous for CBA/ $\mathrm{CaH}$ or $\mathrm{BALB} / \mathrm{cBy}$. These results are similar to the effect observed in the analysis of the CCBAF2 QTL. Although the mechanisms are currently unclear, there have been reported cases in which heterozygous genotypes are advantageous over either homozygous genotype. A well-documented case of this phenomenon is the sickle cell gene haemoglobin
$(\mathrm{Hb})$ in humans. Carriers of the sickle cell trait are heterozygous for the $\mathrm{Hb}$ genotype (HbAS) and this heterozygosity seems to be protective against malaria, with lower mortality and parasitaemia when compared with either homozygous $\mathrm{Hb}$ genotypes (HbSS and HbAA) [22]. The differences observed in the phenotypes of the incipient congenics in our study were dependent on the recipient genome and this highlights the probable contribution of epistatic interaction effects from the background.

The region containing the Spir2 locus is approximately $39 \mathrm{Mb}$ in length and overlaps with several published QTL involved in immunity or susceptibility to infection; Bbaa1 (Borrelia burgdorferi - associated arthritis 1), a locus contributing to severity of arthritis induced by B. burgdorferi infection [23], Lprm1 (lymphoproliferation modifier 1), a QTL conferring susceptibility to autoimmune vasculitis [24], Sle2 (systemic lupus erythmatosus susceptibility 2), contributing to $\mathrm{B}$ cell hyperactivity, an immunogenic phenotype caused by the autoimmune disease systemic lupus erythmatosus [25,26] and Marif1 (macrophageassociated risk inflammatory factor 1) which affects inflammatory phenotypes of macrophages such as secretion of TNFa and IL-12p40 [27]. It is premature to speculate whether any of the genes underlying these QTLs are shared, but the Marif1 locus is of interest because of the opposite Th1/Th2 bias of the inbred strains $\mathrm{BALB} / \mathrm{c}$ and $\mathrm{CBA} / \mathrm{Ca}$ [28] and because we [29] and others [30] have shown that 


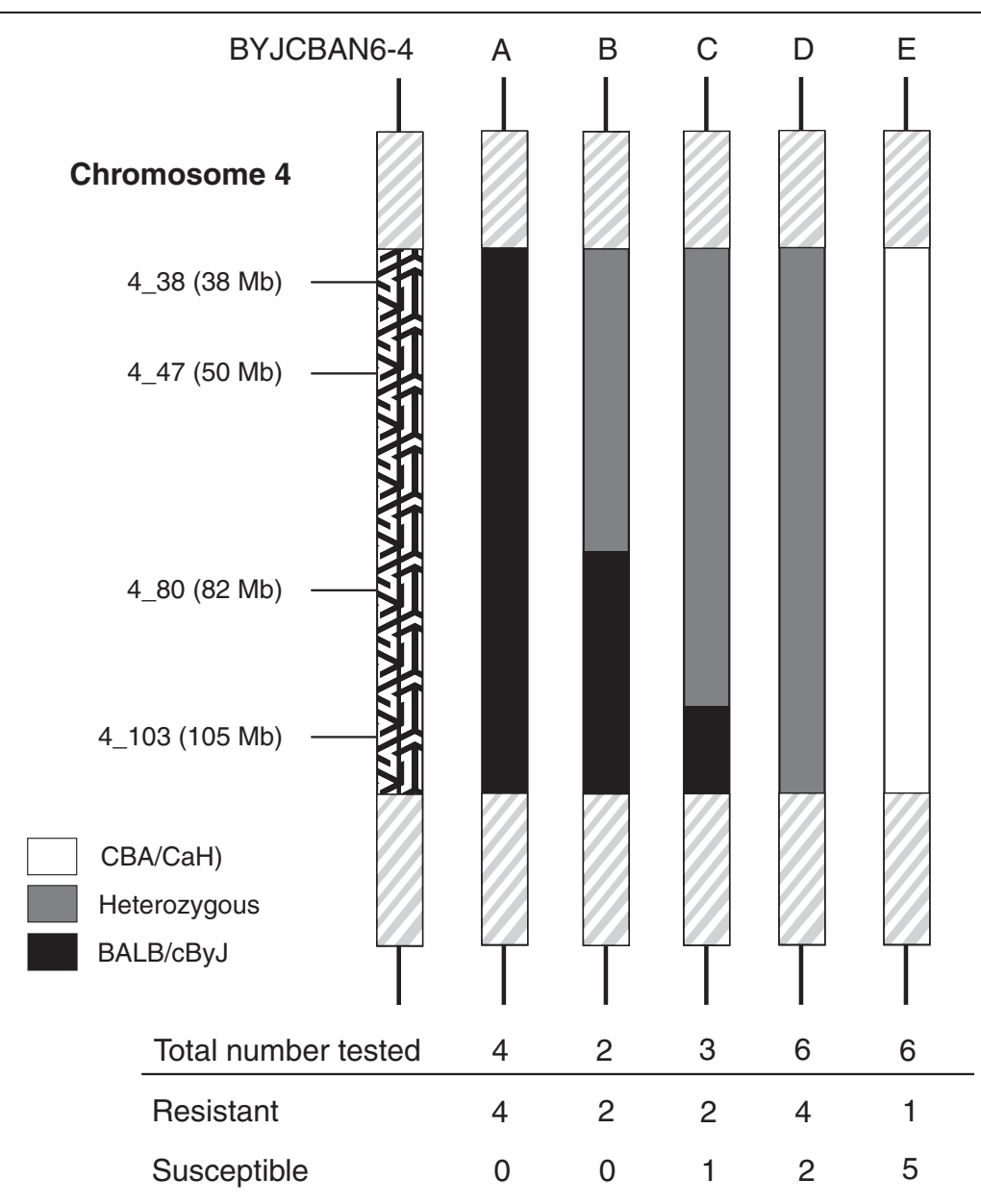

Figure 7 Diagram representing chromosome 4 from the different BYJCBAN6-4 haplotype groups named BYJCBAN6-4-A to E. The area spanning SNP markers 4_38 to 4_103 is highlighted with the positions of each the SNP markers used for genotyping shown on the left. Areas outside of these SNP markers (grey diagonal lines) are either homozygous for the recipient strain or heterozygous. Black represents regions homozygous for BALB/CByJ, white for regions homozygous for CBA/CaH and those in grey are heterozygous. The total number of mice from each group that were tested can be seen with the numbers of resistant and susceptible mice below.

macrophages play an important role in susceptibility to pneumococci.

The Spir2 locus region contains 169 genes, according to Ensembl V.65. One strong candidate gene, based on it's known role in regulating innate immunity, is Tlr4 [31], but non-synonymous differences in the sequence of Tlr4 between BALB/cOlaHsd and CBA/CaOlaHsd were found to be common to other inbred strains, making it less likely to play a role in the Spir2 locus (data not shown). It is clear that sequence analysis of the entire QTL would aid the prioritisation of other candidate disease genes for further study.

\section{Conclusions}

The Spir1 and Spir2 loci are linked significantly to both bacteraemia and survival time ([13] and this work). This may mean that the principle cause of death, in our model of pneumonia, is bacteraemia and the downstream inflammatory effects it precipitates in the host.

\section{Methods}

\section{Ethics statement}

This study was performed in strict accordance with U.K. Home Office guidelines. Both the U.K. Home Office and the University of Leicester ethics committee approved the protocol. Every effort was made to minimize suffering and in bacterial infection experiments mice were humanely culled if they became lethargic. All animal experiments were carried out at the University of Leicester.

\section{Mice}

BALB/cByJ and CBA/CaH were obtained from the MRC Mary Lyon Centre (MLC) in Harwell and were used for the congenic breeding scheme. The congenic breeding 

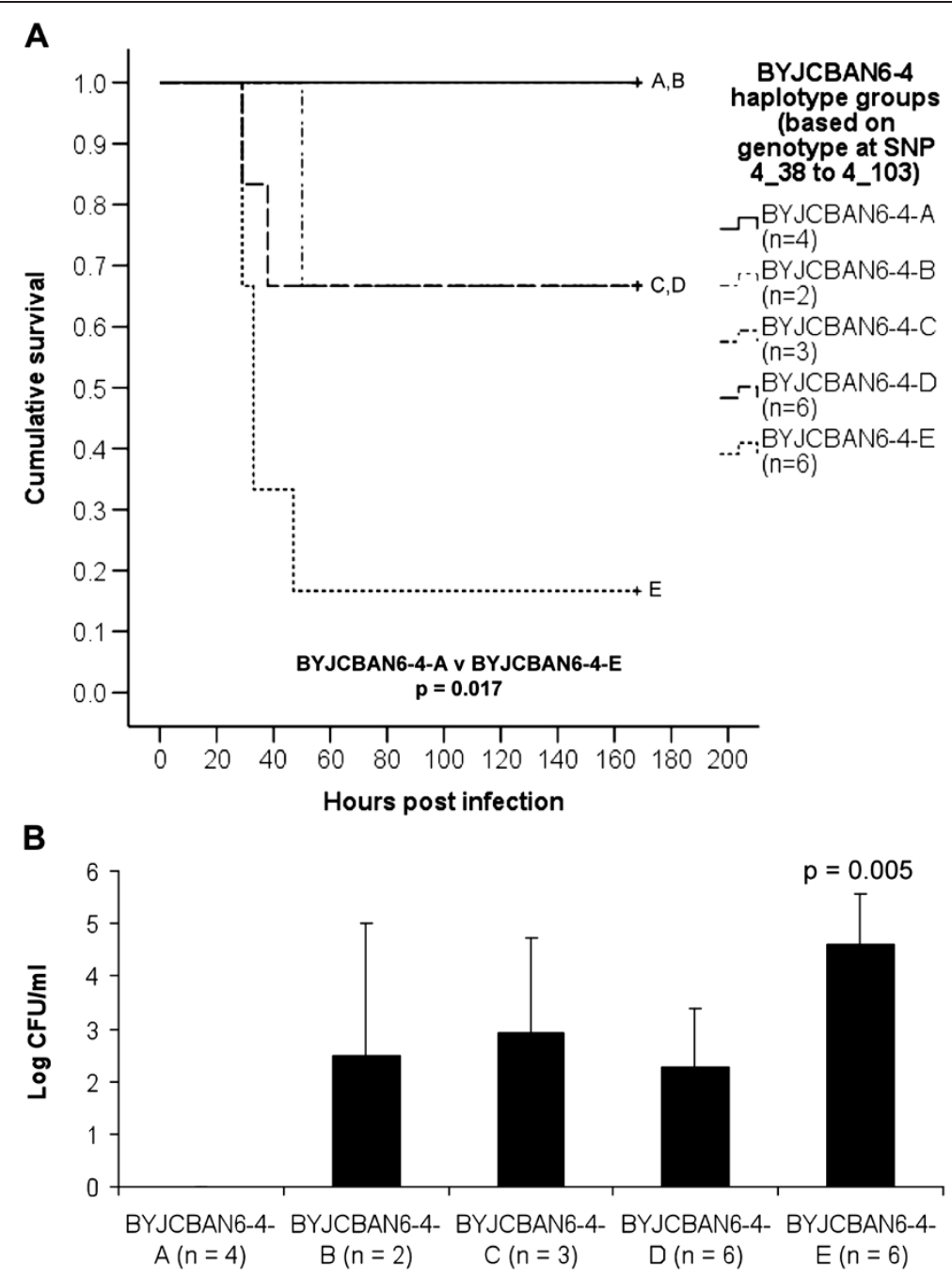

Figure 8 Infection phenotypes for BYJCBAN6-4 mice with different haplotypes. (A) Kaplan-Meier survival curves showing the cumulative survival for the BYJCBAN6-4 haplotypes. The survival curve of each group is labelled (A to E). Statistical significance (pair-wise comparison with the Log Rank test) is indicated by p values on the graph. (B) Average numbers of S. pneumoniae (Log CFU/ml) in the blood at 24 hours postinfection for each BYJCBAN6-4 haplotype. Error bars represent the standard error of the mean. The numbers of mice in each group are shown in brackets. Statistical significance (compared to BYJCBAN6-4-A, unpaired $t$-test) is indicated by $p$ values on the graph.

was performed at the MLC and infection studies were done at the University of Leicester.

\section{Congenic breeding scheme}

A semi-speed congenic breeding scheme was implemented in this study. An alternating set of 73 SNP markers, spanning the genome, with an average spacing of $28 \mathrm{Mb}$, was used in order to reduce cost and time and ensure good coverage of the genome [32]. During the first two backcross generations (N2 and N3) the alternate genome scan was performed where at least 20 male progeny for each generation, which were heterozygous for the QTL, were typed genome wide in order to select the best male for breeding [32,33]. The next generations (from N4 to N6 or N7) were only genotyped for the chromosome 4 QTL markers. Once the mice reached the N6 or N7 generation, female mice heterozygous for the region of interest were crossed to males heterozygous for the same SNP markers to produce offspring for infection testing. Whole litters were tested for susceptibility to S. pneumoniae.

\section{Bacterial culture and infections}

Incipient congenic mice were infected intranasally with S. pneumoniae D39 as described previously $[12,13]$. Blood was taken at 24 hours post-infection from the tail vein (for bacterial culture) and survival times of the mice were recorded. Mice that survived to the end point of the experiment (more than 168 hours) were considered resistant. All mice that succumbed to infection (the 
endpoint was severely lethargic) and had survival times less than 168 hours were considered susceptible.

\section{DNA extractions}

For QTL mapping, DNA from the (BALB/cOlaHsd $\times$ $\mathrm{CBA} / \mathrm{CaOlaHsd}) \mathrm{F}_{2} \quad\left(\mathrm{CCBAF}_{2}\right)$ intercross, reported in Denny et al., [13], was used. DNA samples from $\mathrm{CCBAF}_{2}$ mice from the phenotypic extremes were selected for QTL mapping. Thirty eight of the most susceptible mice (survival $<46$ hours and high levels of bacteria in blood) and thirty eight of the most resistant mice (survival $\geq 168$ hours and no bacteria in blood) were genotyped for linkage analysis. DNA was diluted to $5 \mathrm{ng} / \mu \mathrm{l}$ in double-distilled $\mathrm{H}_{2} \mathrm{O}$.

In congenic breeding, DNA was extracted from ear clips using the Viagen DirectPCR ear lysis reagent (Viagen Biotech cat 402-E). $195 \mu \mathrm{l}$ Direct PCR lysis reagent and $5 \mu \mathrm{l}$ proteinase $\mathrm{K}(10 \mathrm{mg} / \mathrm{ml})$ was added to each earclip and incubated overnight at $55^{\circ} \mathrm{C}$. After digestion, the samples were heated to $85^{\circ} \mathrm{C}$ for $45 \mathrm{~min}$ and centrifuged for 10 seconds. $1 \mu$ l of lysate was used in each PCR reaction.

\section{SNP panel}

The $76 \mathrm{CCBAF}_{2}$ mice from the phenotypic extremes were genotyped by Pyrosequencing (as described below) across the whole genome using a panel of 73 SNPs with an average spacing of $28 \mathrm{Mb}$. Chromosome 4 was genotyped with an additional set of SNP markers to narrow down areas of suggestive linkage. A total of nine SNPs for chromosome 4 were typed by Pyrosequencing. Genotyping data from chromosome 4 microsatellite markers used in Denny et al., [13] were incorporated into the analysis. There were a total of 5 microsatellite markers that had been typed on 38 of the mice. Details of the SNP primers can be found in Additional file 4: Table S1.

\section{Primer design}

SNPs were selected using the Mouse Phenome Database (http://phenome.jax.org/pub-cgi/phenome/mpdcgi? $\mathrm{rtn}=$ docs/home) and the SNP sequences were exported from the NCBI Entrez SNP database (http://www.ncbi.nlm. nih.gov/sites/entrez). Primers for Pyrosequencing were designed using the PSQ Assay Design software from Biotage AB. Primer sets of three primers for each SNP were designed, one pair of primers for the PCR (one of which was biotinylated) and a sequencing primer for the Pyrosequencing reaction. The minimum and maximum $\mathrm{T}_{\mathrm{m}}$ for the PCR primers were 64 to $66^{\circ} \mathrm{C}$. The sequencing primers were designed with a maximum distance of three bases from the SNP. Primers were manufactured by either Biomers.net or MWG-Biotech.

\section{PCR}

$10 \mu \mathrm{l}$ PCR reactions were set up using $5 \mu \mathrm{l}$ Qiagen Taq PCR master mix (cat. 201445), $0.2 \mu$ l forward primer and $0.2 \mu \mathrm{l}$ reverse primer (at $10 \mathrm{pmol} / \mu \mathrm{l}$ ), 2.6 - $3.6 \mu \mathrm{l} \mathrm{nu}-$ clease free water and $1-2 \mu \mathrm{l} \operatorname{DNA}(\sim 5 \mathrm{ng} / \mu \mathrm{l})$. PCR reactions were run using the following PCR program: $95^{\circ} \mathrm{C}$ for $5 \mathrm{~min}$, followed by 45 cycles of $95^{\circ} \mathrm{C}$ for $15 \mathrm{sec}, 60^{\circ} \mathrm{C}$ for $30 \mathrm{sec}$ and $72^{\circ} \mathrm{C}$ for $15 \mathrm{sec}$. The final extension step was for $5 \mathrm{~min}$ at $72^{\circ} \mathrm{C}$.

\section{Pyrosequencing}

$10 \mu \mathrm{l}$ PCR product, $2 \mu \mathrm{l}$ streptavidin-Sepharose beads (GE Healthcare 17-5113-01), $38 \mu \mathrm{l}$ binding buffer (Biotage AB 40-0033) and $30 \mu \mathrm{l} \mathrm{H}_{2} \mathrm{O}$ were combined in a 96-well plate and mixed vigorously on a plate shaker for $5 \mathrm{~min}$ so that the biotin-labelled PCR product bound to the streptavidin coated beads. The PCR products were then prepared using a vacuum work table (Biotage $A B$ ). The biotinylated PCR products, attached to the filter probes of the vacuum tool, were immersed in $70 \%(\mathrm{v} / \mathrm{v})$ ethanol for 5 seconds, denatured in PyroMark Denaturation solution (Biotage AB 40-0034) for $5 \mathrm{sec}$ (allowing only the biotin labelled strand of the PCR product to stay attached to the filter probes) and immersed in 1X PyroMark Wash buffer (Biotage AB 40-0035) for 5 sec. The single-stranded PCR products were then re-suspended in a PSQ HS 96-well plate containing $0.5 \mu \mathrm{l}$ sequencing primer (at $10 \mathrm{pmol} / \mu \mathrm{l}$ ) and $11.5 \mu \mathrm{l}$ annealing buffer (Biotage $\mathrm{AB}$ 40-0036) per well.

The plate was incubated at $80^{\circ} \mathrm{C}$ for 2 minutes to allow the sequencing primer to anneal to the single-stranded PCR product. The PSQ 96-well plate and a PSQ HS 96 capillary dispensing tip holder (Biotage AB 60-0211) containing enzyme, substrate and dNTPs (PyroGold reagent kit Biotage AB 40-0047), were placed into a PSQ HS 96 Pyrosequencer (Biotage AB). The assays were performed and the data were analysed using the SNP software (Biotage AB).

\section{Linkage analysis}

SNP genotype data from the $76 \mathrm{CCBAF}_{2}$ mice and phenotype data from 168 non-genotyped $\mathrm{CCBAF}_{2}$ mice were incorporated into the linkage analysis. Data were analysed using R-QTL for non parametric analysis [34]. One thousand permutation tests were performed in order to establish genome-wide LOD significance thresholds at the $90 \%$ and 95\% confidence level. Loci with LOD scores exceeding the $90 \%$ confidence level were identified as suggestive and those exceeding the 95\% confidence level were identified as significant regions of linkage. The confidence interval for each QTL was determined by a one LOD support interval ( -1 LOD drop from the peak of linkage). For the marker at the peak of each QTL, data were analysed using a Chi-squared $\left(\chi^{2}\right)$ test. Numbers of mice resistant and 
susceptible to pneumococcal infection were grouped by their genotype at the appropriate SNP marker. Observed numbers of mice were compared to the expected numbers (1:2:1 ratio) if genotype had no effect $\left(x^{2}\right)$. To investigate the effect the genotype, at the peak of linkage, on time to reach a moribund state, Kaplan Meier survival analysis was performed using the statistics package SPSS (version 17). The difference between the survival curves was analysed using the Log Rank test. p values of less than 0.05 were considered significant. The heritability equation $\left(1-10^{-2 \mathrm{LOD} / \mathrm{n}}\right)$ was used to estimate the percentage of phenotypic variance accounted for by the QTL.

\section{Congenic breeding data analysis}

Survival data and bacteraemia data were firstly analysed on a single SNP basis for chromosome 4. Mice were then grouped into shared haplotypes based on the combination of SNPs for chromosome 4 from SNP 4_38 to SNP 4_103. Survival data were analysed using KaplanMeier survival analysis with Log Rank pair wise comparison for statistical significance using SPSS (version 17). Bacteraemia data for the three genotypes (BALB/ cByJ homozygous, $\mathrm{CBA} / \mathrm{CaH}$ homozygous or heterozygous) were compared for each SNP using a two-tailed unpaired Student $t$-test. Numbers of bacteria in the blood in the haplotypes were compared in the same way. Results with $\mathrm{p}$ values less than 0.05 were considered significant.

\section{Additional files}

Additional file 1: Table S2. Proportion of CBABYJN7-4 mice resistant or susceptible to pneumococcal infection, grouped by their genotype at either SNP 4_80 or SNP 4_103.

Additional file 2: Figure S1. Kaplan-Meier survival curves showing the cumulative survival for the CBABYJN7-4 mice, based on genotype at SNP 4_103. The survival curve of each group is labelled by genotype.

Additional file 3: Figure S2. A) Kaplan-Meier survival curves showing the cumulative survival for the BYJCBAN6-4 mice, based on genotype at SNP 4_38. The survival curve of each group is labelled by genotype. B) Kaplan-Meier survival curves showing the cumulative survival for the BYJCBAN6-4 mice, based on genotype at SNP 4_103. The survival curve of each group is labelled by genotype.

Additional file 4: Table S1. Panel of PCR and Pyrosequencing primers used to genotype SNPs in CCBAF2 mice.

\section{Abbreviations}

df: Degrees of freedom; LOD: Logarithm of odds; QTL: Quantitative trait locus; SNP: Single nucleotide polymorphism; Spirz: S. pneumoniae infection resistance 2 .

\section{Competing interests}

The authors declare that they have no competing interests.

\section{Authors' contributions}

LW performed the CCBAF 2 and congenic SNP genotyping, management of the congenic breeding scheme, QTL and congenic mapping data analysis and interpretation of the results. DRN and VEF designed and performed PCR assays and sequencing. VEF performed the infection studies and bacterial culture. PWA, AK and PD conceived and designed the experiments. Overall project leadership was shared jointly by PW Andrew and Paul Denny. All authors read and approved the final manuscript.

\section{Acknowledgements}

We thank Anne Southwell, Debra Brooker, Jackie Harrison, Elaine Whitehill and Sara Wells for technical support and an anonymous reviewer for improvements to the manuscript. This work was supported by a UK Medical Research Council grant awarded to Peter W Andrew \& Aras Kadioglu. Peter W Andrew and Paul Denny jointly directed the project.

\section{Author details}

${ }^{1}$ MRC Mammalian Genetics Unit, Harwell, Oxon OX11 ORD, UK. ${ }^{2}$ Department of Infection, Immunity and Inflammation, University of Leicester, Leicester, UK. ${ }^{3}$ Department of Clinical Infection Microbiology \& Immunology, Institute of Infection \& Global Health, University of Liverpool, Liverpool, UK.

Received: 18 September 2012 Accepted: 4 April 2013

Published: 11 April 2013

\section{References}

1. O'Brien KL, Wolfson $L$, Watt JP, Henkle E, Deloria-Knoll M, McCall N, Lee E, Mulholland K, Levine OS, Cherian T: Burden of disease caused by Streptococcus pneumoniae in children younger than 5 years: global estimates. Lancet 2009, 374(9693):893-902.

2. Coffey TJ, Dowson CG, Daniels M, Zhou J, Martin C, Spratt BG, Musser JM: Horizontal transfer of multiple penicillin-binding protein genes, and capsular biosynthetic genes, in natural populations of Streptococcus pneumoniae. Mol Microbiol 1991, 5(9):2255-2260.

3. Coffey TJ, Enright MC, Daniels M, Morona JK, Morona R, Hryniewicz W, Paton JC, Spratt BG: Recombinational exchanges at the capsular polysaccharide biosynthetic locus lead to frequent serotype changes among natural isolates of Streptococcus pneumoniae. Mol Microbiol 1998, 27(1):73-83.

4. Nuermberger EL, Bishai WR: Antibiotic resistance in Streptococcus pneumoniae: what does the future hold? Clin Infect Dis 2004, 38(Suppl 4):S363-S371.

5. Appelbaum PC, Bhamjee A, Scragg JN, Hallett AF, Bowen AJ, Cooper RC: Streptococcus pneumoniae resistant to penicillin and chloramphenicol. Lancet 1977, 2(8046):995-997.

6. Malaty HM, Engstrand L, Pedersen NL, Graham DY: Helicobacter pylori infection: genetic and environmental influences. A study of twins. Ann Intern Med 1994, 120(12):982-986

7. Haltia M, Kovanen J, Van Crevel H, Bots GT, Stefanko S: Familial CreutzfeldtJakob disease. J Neurol Sci 1979, 42(3):381-389.

8. Sorensen TI, Nielsen GG, Andersen PK, Teasdale TW: Genetic and environmental influences on premature death in adult adoptees. N Engl J Med 1988, 318(12):727-732.

9. Couvreur J, Desmonts G, Girre JY: Congenital toxoplasmosis in twins: a series of 14 pairs of twins: absence of infection in one twin in two pairs. J Pediatr 1976, 89(2):235-240.

10. Vidal SM, Malo D, Vogan K, Skamene E, Gros P: Natural resistance to infection with intracellular parasites: isolation of a candidate for Bcg. Cell 1993, 73(3):469-485.

11. Bellamy R, Ruwende C, Corrah T, McAdam KP, Whittle HC, Hill AV: Variations in the NRAMP1 gene and susceptibility to tuberculosis in West Africans. N Engl J Med 1998, 338(10):640-644

12. Gingles NA, Alexander JE, Kadioglu A, Andrew PW, Kerr A, Mitchell TJ, Hopes E, Denny $P$, Brown $S$, Jones $H B$, et al: Role of genetic resistance in invasive pneumococcal infection: identification and study of susceptibility and resistance in inbred mouse strains. Infect Immun 2001, 69(1):426-434.

13. Denny P, Hopes E, Gingles N, Broman KW, McPheat W, Morten J, Alexander J, Andrew PW, Brown SD: A major locus conferring susceptibility to infection by Streptococcus pneumoniae in mice. Mamm Genome 2003, 14(7):448-453.

14. Eklund C, Huttunen R, Syrjanen J, Laine J, Vuento R, Hurme M: Polymorphism of the C-reactive protein gene is associated with mortality in bacteraemia. Scand I Infect Dis 2006, 38(11-12):1069-1073.

15. Roy S, Knox K, Segal S, Griffiths D, Moore CE, Welsh KI, Smarason A, Day NP, McPheat WL, Crook DW, et al: MBL genotype and risk of invasive pneumococcal disease: a case-control study. Lancet 2002, 359(9317):1569-1573. 
16. Khor CC, Chapman SJ, Vannberg FO, Dunne A, Murphy C, Ling EY, Frodsham AJ, Walley AJ, Kyrieleis O, Khan A, et al: A Mal functional variant is associated with protection against invasive pneumococcal disease, bacteremia, malaria and tuberculosis. Nat Genet 2007, 39(4):523-528.

17. Chapman SJ, Khor CC, Vannberg FO, Maskell NA, Davies CW, Hedley EL, Segal S, Moore CE, Knox K, Day NP, et al: PTPN22 and invasive bacterial disease. Nat Genet 2006, 38(5):499-500.

18. Lander ES, Botstein D: Mapping mendelian factors underlying quantitative traits using RFLP linkage maps. Genetics 1989, 121(1):185-199.

19. Corva PM, Medrano JF: Quantitative trait loci (QTLs) mapping for growth traits in the mouse: a review. Genet Sel Evol 2001, 33(2):105-132.

20. Darvasi A, Soller M: Selective DNA pooling for determination of linkage between a molecular marker and a quantitative trait locus. Genetics 1994, 138(4):1365-1373.

21. Darvasi A: The effect of selective genotyping on QTL mapping accuracy. Mamm Genome 1997, 8(1):67-68.

22. Aidoo M, Terlouw DJ, Kolczak MS, McElroy PD, ter Kuile FO, Kariuki S, Nahlen BL, Lal AA, Udhayakumar V: Protective effects of the sickle cell gene against malaria morbidity and mortality. Lancet 2002, 359(9314):1311-1312.

23. Weis JJ, McCracken BA, Ma Y, Fairbairn D, Roper RJ, Morrison TB, Weis JH, Zachary JF, Doerge RW, Teuscher C: Identification of quantitative trait loci governing arthritis severity and humoral responses in the murine model of Lyme disease. J Immunol 1999, 162(2):948-956.

24. Wang Y, Nose M, Kamoto T, Nishimura M, Hiai H: Host modifier genes affect mouse autoimmunity induced by the Ipr gene. Am J Pathol 1997, 151(6):1791-1798.

25. Morel L, Rudofsky UH, Longmate JA, Schiffenbauer J, Wakeland EK: Polygenic control of susceptibility to murine systemic lupus erythematosus. Immunity 1994, 1(3):219-229.

26. Mohan C, Morel L, Yang P, Wakeland EK: Genetic dissection of systemic lupus erythematosus pathogenesis: Sle2 on murine chromosome 4 leads to B cell hyperactivity. J Immunol 1997, 159(1):454-465.

27. Fijneman RJ, Vos M, Berkhof J, Demant P, Kraal G: Genetic analysis of macrophage characteristics as a tool to identify tumor susceptibility genes: mapping of three macrophage-associated risk inflammatory factors, marif1, marif2, and marif3. Cancer Res 2004, 64(10):3458-3464.

28. Stacey KJ, Blackwell JM: Immunostimulatory DNA as an adjuvant in vaccination against Leishmania major. Infect Immun 1999, 67(8):3719-3726.

29. Ripoll VM, Kadioglu A, Cox R, Hume DA, Denny P: Macrophages from $B A L B / C$ and CBA/Ca mice differ in their cellular responses to Streptococcus pneumoniae. J Leukoc Biol 2010, 87(4):735-741.

30. Marriott HM, Dockrell DH: The role of the macrophage in lung disease mediated by bacteria. Exp Lung Res 2007, 33(10):493-505.

31. Klein M, Obermaier B, Angele B, Pfister HW, Wagner H, Koedel U, Kirschning CJ: Innate immunity to pneumococcal infection of the central nervous system depends on toll-like receptor (TLR) 2 and TLR4. J Infect Dis 2008, 198(7):1028-1036.

32. Markel P, Shu P, Ebeling C, Carlson GA, Nagle DL, Smutko JS, Moore KJ: Theoretical and empirical issues for marker-assisted breeding of congenic mouse strains. Nat Genet 1997, 17(3):280-284.

33. Armstrong NJ, Brodnicki TC, Speed TP: Mind the gap: analysis of markerassisted breeding strategies for inbred mouse strains. Mamm Genome 2006, 17(4):273-287.

34. Broman KW, Wu H, Sen S, Churchill GA: R/qtl: QTL mapping in experimental crosses. Bioinformatics 2003, 19(7):889-890.

doi:10.1186/1471-2164-14-242

Cite this article as: Wisby et al: Spir2; a novel QTL on chromosome 4 contributes to susceptibility to pneumococcal infection in mice. $B M C$ Genomics 2013 14:242.

\section{Submit your next manuscript to BioMed Central and take full advantage of:}

- Convenient online submission

- Thorough peer review

- No space constraints or color figure charges

- Immediate publication on acceptance

- Inclusion in PubMed, CAS, Scopus and Google Scholar

- Research which is freely available for redistribution

Submit your manuscript at www.biomedcentral.com/submit 